\title{
The effects of providing portable shade at pasture on dairy cow behavior and physiology
}

\author{
S. Palacio, ${ }^{1}$ R. Bergeron, S. Lachance, and E. Vasseur \\ Organic Dairy Research Centre, Université de Guelph, Campus d'Alfred, Alfred, ON, KOB 1A0, Canada
}

\begin{abstract}
Access to pasture has advantages for cows such as reduced lameness and improved udder health, but also may expose cows to stressors such as extreme heat. The objective of this study was to understand how portable shade affected physiological and behavioral responses of pastured dairy cows in a Canadian summer. Over 8 wk, a total of 24 lactating Holstein cows were separated into 2 treatments, one with access to shade and a control without access to shade. The cows were pastured in groups of 4 , with 3 field sections per treatment. Instantaneous scan sampling of behaviors (drinking, lying, grazing, other) performed in the shade or not were recorded every $5 \mathrm{~min}$ for $3 \mathrm{~h} / \mathrm{d}$ during the hottest part of the day (peak hours: 1130-1530 h) 3 d/wk. Ambient temperature, humidity, and vaginal temperature were recorded at 10-min intervals. Daily milk production was also recorded. Differences between treatments by week were analyzed using the generalized linear mixed model with group as random effect and treatment as fixed effect. Cows with shade access were observed at the water trough up to 6.42 times less and lying down up to 1.75 times more. Cows with shade access grazed up to 1.5 times more but only when the temperature-humidity index was above their comfort threshold $(\geq 72)$ during the hottest part of the day (wk 2 ). Cows sought shade when it was made available, but spent less than half of their time observed (\%) in the shade $(40.8 \pm 4.67)$ with the exception of wk 2 when most of the time was spent under the shade $(74.3 \pm$ 4.77). Daily lying time was highest during peak hours for cows with shade access. However, no overall difference in total lying time between the 2 treatments was observed. No differences were found in vaginal temperature or milk production between treatments with the exception of wk 1 for daily milk production, which was higher for cows in the control treatment. In
\end{abstract}

\footnotetext{
Received October 3, 2014.

Accepted May 28, 2015.

${ }^{1}$ Corresponding author: spalacio89@gmail.com
}

conclusion, cows sought shade when it was provided at pasture, whereas cows without access to shade seemed to alter their behavior to cope with heat stress, as seen from the lack of physiological differences between treatments. The results indicate that providing cows with access to pasture under a temperate climate does not seem to have any detrimental physiological or production effects and providing them with shade can potentially decrease production costs and help with water conservation strategies as fewer cows were observed at the water when shade was provided.

Key words: dairy cow, portable shade, behavior, heat stress

\section{INTRODUCTION}

Access to pasture has been shown to have several advantages for dairy cow welfare, such as reduced lameness and improved udder health (Washburn et al., 2002; Hernandez-Mendo et al., 2007), as well the ability to perform a wider range of natural behaviors. However, under certain conditions, pastured cows may be exposed to undue stress, such as extreme heat that can increase water consumption, decrease feed intake, increase body temperature, and lower milk production (Kadzere et al., 2002). Pastured cows may also be exposed to fly attacks, which may be exacerbated by increased heat.

Dairy cows have been reported to spend less time at pasture as the temperature-humidity index (THI) increases when given the choice between pasture or freestall barn (Legrand et al., 2009), and to seek shade when air temperature and solar radiation increase (Kendall et al., 2006). The comfort threshold for Holstein dairy cattle has been established at a THI of $\geq 72$ (Ravagnolo et al., 2000). In Canadian temperate regions, THI can exceed the comfort threshold for short periods (i.e., $1 \mathrm{~d}$ to 1 wk at a time), and such a short-term moderate heat stress has been shown to increase vaginal temperature and decrease milk production in dairy cows (Ominski et al., 2002). Beede and Collier (1986) speculated that thermal stress can seriously affect animals in temperate regions because they are not adapted to deal with heat stress conditions. 
Providing access to shade at pasture can help alleviate some of the effects of heat stress such as increased time at the waterer (Schütz et al., 2010) and increased body temperature (Valtorta et al., 1997), and it can also increase production (Kendall et al., 2006). Cows have been reported to be highly motivated to use shade in warm weather (Schütz et al., 2008) and prefer shade over sprinklers at pasture even though sprinklers are a more effective cooling method (Schütz et al., 2011).

Although access to shade can help diminish several negative effects brought on by an increased heat load while at pasture, Kendall et al. (2006) found that cows with access to shade grazed less during the hottest part of the day compared with cows without access to shade. In intensive grazing rotational systems required by high-yielding pastured cows, fresh strips of pasture are provided to the cows twice a day. When temperatures are above the comfort threshold, a portable shade might help diminish the potential lower grazing time by providing fresh forage near or under the shade on a daily basis instead of forcing the cows to remain under a permanent shade structure located further from fresh pasture. The objective of this study was to understand how portable shade systems affect physiological and behavioral responses of dairy cattle during an Eastern Canadian summer.

\section{MATERIALS AND METHODS}

\section{Animals and Treatments}

The study was conducted at the Organic Dairy Research Centre of the University of Guelph (Alfred, Ontario, Canada) located in the Saint Lawrence Lowlands climatic region. The study lasted a total of $8 \mathrm{wk}$, from July 8 to August 30, 2013. Twenty-four Holstein lactating dairy cows were used. At the start of the study, cows were on average ( \pm standard deviation) $212 \pm 95$ DIM with a lactation number of $2.33 \pm 1.20$ and an annual milk production of 9,795 $\pm 1,199 \mathrm{~kg}$.

Cows were assigned to 12 experimental pairs ( $\mathrm{n}=$ 2 cows). Treatment groups were balanced for days in milk, lactation number, annual milk production, and coat color. Coat color was determined through visual observation by 2 observers on all 24 cows, and an average for each cow was determined. Cows were classified into 3 different color groups: mostly white (4 cows), mostly black (12 cows), or in between (8 cows).

All cows had previous experience with pasture as they are kept on pasture all day except during the 2 daily milkings and follow organic management practices. Each pair was assigned to 1 of 2 treatments, access to shade, and no access to shade for the first $4 \mathrm{wk}$ of the study, and was switched to the other treatment on wk 5 for the remaining 4 wk. Each week, one pair was combined with a new pair from the same treatment. The combined pair groups $(\mathrm{n}=4)$ were randomly assigned to a new field section (3 field sections for each treatment) measuring an average of $280 \mathrm{~m}^{2}(\mathrm{SD}=87$ $\mathrm{m}^{2}$ ), with detailed group organization provided in Table 1. Animals in the shade treatment were given access to a rectangular portable shade structure $(3.05 \times 6.1 \mathrm{~m}$; METEC Metal Technology Inc., Vankleek Hill, Ontario, Canada) giving each cow $4.65 \mathrm{~m}^{2}$ of available shade and possible grazing area underneath the structure. This is in accordance with the recommended space of 3.72 to $5.57 \mathrm{~m}^{2}$ of shade per cow (Higgins et al., 2011) with one structure per field section (3 structures in total). Solar protection was provided by a black shade cloth placed flat as the roof of the structure $(80 \%$ of solar radiation protection; GGS Structures Inc., Lincoln, Ontario, Canada). Shade structures were always placed with the short side facing north to provide as much shade as possible throughout the day. All cows were given a habituation period of one wk to the shade structures before the beginning of the study as well as to the presence of the observers. Shade structures were moved daily with a tractor to follow the cows and fresh pasture. Cows were kept in the field section from 1000 to $1630 \mathrm{~h}$ for $5 \mathrm{~d}$ a week. From evening to morning milking, cows were all kept together in a separate pasture. Water was provided ad libitum with a trough $(1.30 \times 0.80 \mathrm{~m})$ provided in each of the field sections, from which all 4 cows per section could drink simultaneously. Cows were milked twice a day (around $0700 \mathrm{~h}$ and at $1700 \mathrm{~h}$ ). After the morning milking, cows were provided with concentrate and minerals to supplement their pasture-based diet.

\section{Climatic Variables}

Air temperature and relative humidity were recorded automatically at 10-min intervals with environmental loggers (Hobo Pro Data loggers, Onset Computer Corp., Bourne, MA) for $4 \mathrm{~d}$ per week (Monday to Thursday). Two data loggers were placed near the experimental pastures, ensuring they were always under the sun. Two data loggers were placed under one of the shade structures directly under the shade cloth on the northeast corner of the structure. Data from the data loggers were downloaded at the end of each experimental week. The THI was calculated using the air temperature and relative humidity following Schütz et al. (2011):

$$
\begin{aligned}
\mathrm{THI}=(1.8 \times & \mathrm{T}+32)-[(0.55-0.0055 \times \mathrm{RH}) \\
& \times(1.8 \times \mathrm{T}-26)],
\end{aligned}
$$


Table 1. Group organization and distribution throughout the 8-wk trial ${ }^{1}$

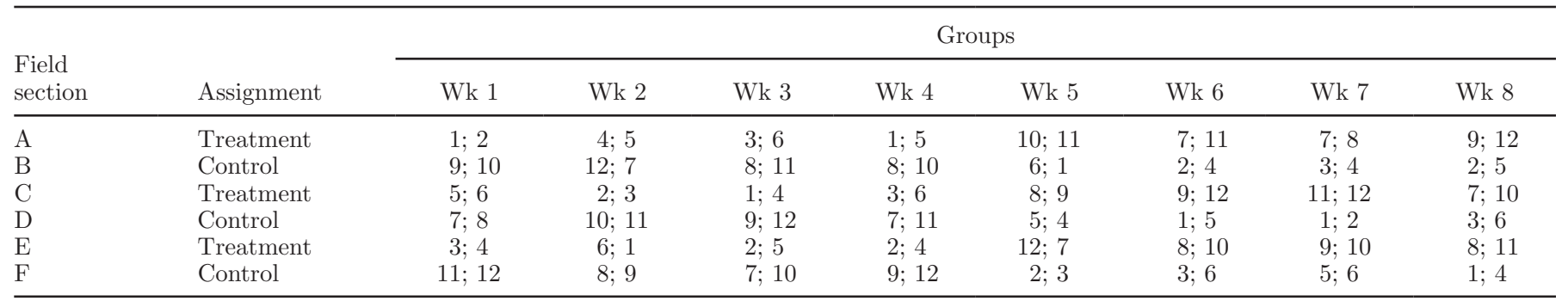

${ }^{1} n=2$ groups of 2 cows/group.

where $\mathrm{T}=$ air temperature $\left({ }^{\circ} \mathrm{C}\right)$ and $\mathrm{RH}=$ relative humidity (\%). Wind speed and rain were recorded from a portable weather station (Onset Computer Corp.) located near the pasture fields. The data were automatically recorded every 30 min for 5 d per week. Light intensity was measured using a light intensity meter (model 401036, Extec Instruments, Nashua, NH) every 30 min during behavioral observations $3 \mathrm{~d}$ per week.

\section{Behavioral Observations}

Lying, grazing, drinking, and other behaviors as well as the location of the cows (under the shade or not) were recorded for each individual cow $(\mathrm{n}=24)$ using instantaneous scan sampling every 5 min for $3 \mathrm{~h}$ during the hottest part of the day with two 30-min breaks in between each hour (peak hours: 1130 to $1530 \mathrm{~h}$ ), on 3 $\mathrm{d}$ of each experimental week (Monday to Thursday).

Lying was defined as the animal having her flank in contact with the ground. Grazing was defined as the animal standing or walking with her head down (below back level); the act of grazing did not necessarily involve the action of pulling grass from the ground. Drinking was defined as the cow standing and facing the drinker within a 1-m distance; the act of drinking did not necessarily involve the action of swallowing water. Other behaviors were defined as any other activity performed that did not fit into the behavioral categories previously described, and mostly consisted of idling or standing without grazing.

The cow was determined to be under the shade if 2 hooves (front or back) were under the shade structure or if 2 hooves (front or back) were observed to be under the shade cast created by the structure when the shade cast was clearly defined and a shade cast was visible over half of the cow's body, following a combination of Kendall et al. (2006) and Tucker et al. (2008).

Individual cows were identified with color band strips (Vet-Wrap, CoFolex, Andover Coated Products Inc., Salisbury, MA) attached to their neck collars and to the bottom end of the tail. Behavioral observations were recorded by 2 observers simultaneously, with each observer collecting data for half of the cows (3 field sections); observers were located directly outside of the field sections ( 1 to $2 \mathrm{~m}$ away from far end of field section). Observers switched sections every hour. A total of 3 observers were possible, and interobserver repeatability was checked against a trainer regularly during the $8 \mathrm{wk}$ and measured to be between 97.5 and $100 \%$ for all behaviors.

\section{Fly Intensity}

A fly count was manually performed on individual cows $(\mathrm{n}=24)$ during one day of each experimental week by 2 observers on days when behavioral observations were not performed; counting method was modified from Woolley (2013). Fly count was done twice per day between 1130 and $1400 \mathrm{~h}$. The counts were done separately for each section of the cow's body (head, neck, back, left side, right side, flank, udders, front legs, rear legs). The species of flies were divided into 3 groups (horn flies; face, house, and stable flies; and other) when being counted. Total fly intensity (all body parts and all fly species) was determined for each individual cow $(\mathrm{n}=24)$. Cows were sprayed daily with a fly repellent mixture containing 3 essential oils, modified from Lachance and Grange (2014).

\section{Daily Lying Time}

Daily lying time was automatically recorded using activity data loggers (Hobo Pendant G Acceleration Data Logger, Onset Computer Corp.) following Vasseur et al. (2012). Each data logger was placed in a fabric pouch and attached to one hind leg of each cow using Vet-Wrap (CoFolex, Andover Coated Products Inc.) on d 1 of each experimental week. Each week, the hind leg to which the data logger was attached was changed. The data logger was programmed to record the position of the cow (lying or standing) at 1-min intervals. Data were downloaded at the end of each experimental week, 
and duration of individual lying bouts was calculated (Excel Macros, Microsoft Corp., Redmond, WA) for each day.

\section{Body Temperature}

Internal body temperature was recorded automatically every 10 min using temperature loggers (Vemco Ltd., Shad Bay, Nova Scotia, Canada), which were fitted into modified blank vaginal controlled internal drug release insert (CIDR; InterAg, Hamilton, New Zealand) following Schütz et al. (2010). Temperature loggers (n $=12 ; 6$ in each of the shaded or not shaded groups) were inserted into the vaginal cavity of the same cows on d 1 of each experimental week (starting wk 2). Data were downloaded on the last day of each experimental week, and mean and maximum body temperature was calculated for each day over a 24-h period and at peak hours (Excel, Microsoft Corp.).

\section{Milk Production}

Individual milk production was automatically recorded (Dematron 75, GEA Farm Technologies, Bönen, Germany) for morning milking, afternoon milking, and total daily milk for the duration of the study.

\section{Statistical Analysis}

Data were analyzed using SAS software (version 9.2, SAS Institute Inc., Cary, NC). Data were expressed as weekly averages by treatment. Response variables (behavioral activities, fly intensity, daily lying time, vaginal temperature, and milk production) were calculated at the group level and tested for normality using the Shapiro-Wilk test (PROC UNIVARIATE). Differences between treatments were tested using a generalized linear mixed model (GLIMMIX) with group as random effect. The effect of climatic variables on response variables was also tested using GLIMMIX with group as random effect. However, no discernable patterns were observed and therefore results were not reported in the paper. Finally, differences in time spent under or outside the shade for cows with access to shade were tested for lying, standing, and other behaviors as well as overall (all 3 behavioral activities) using Wilcoxon signed rank sum test (PROC UNIVARIATE).

\section{RESULTS}

\section{Climatic Conditions}

Average air temperature, humidity, and THI are summarized in Figure 1. Weekly 24-h THI averages
A. $24 \mathrm{~h}$ period

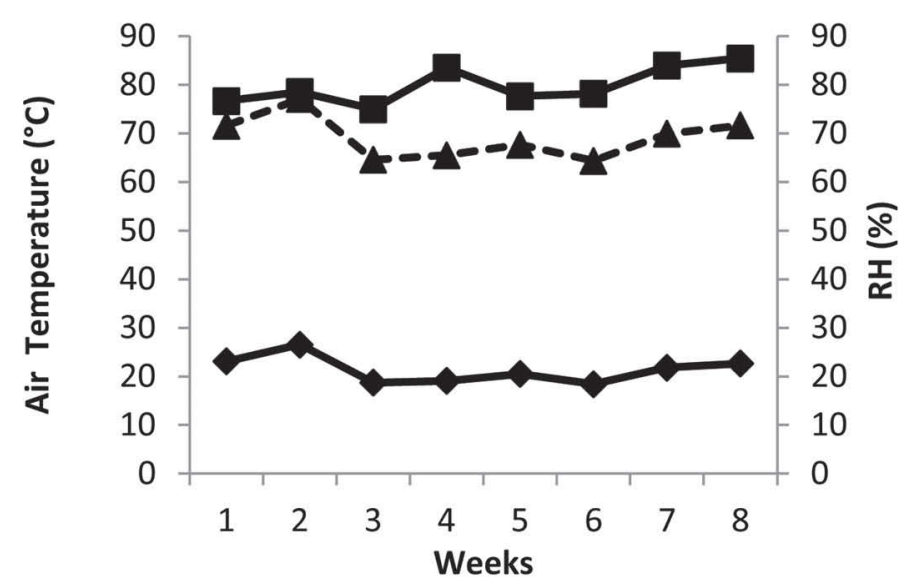

B. Peak hours $(1130-1530$ h)

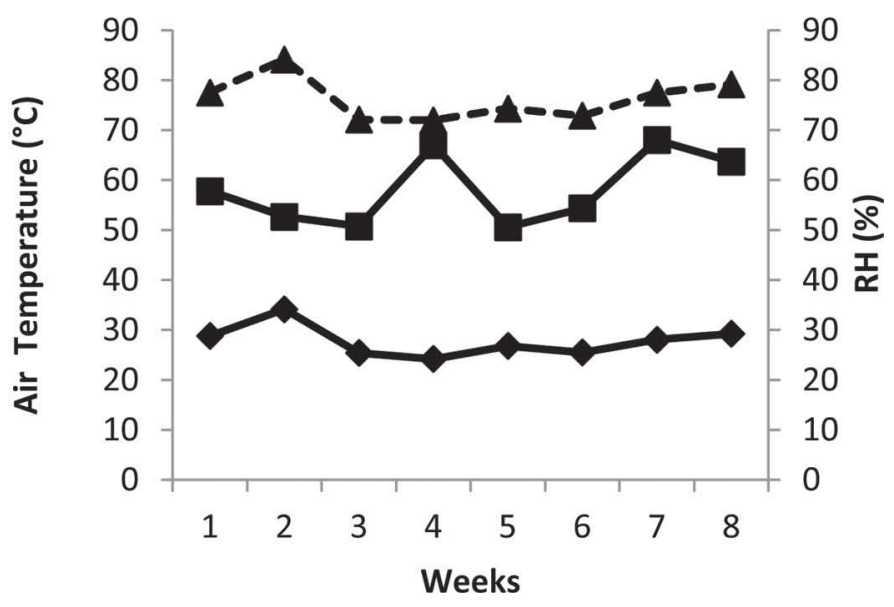

Figure 1. Weekly averages of air temperature (diamond with solid line), relative humidity ( $\mathrm{RH}$, square with solid line), and temperaturehumidity index (THI, triangle with dotted line) over $24 \mathrm{~h}$ (A) and peak hours (B).

were all below the thermal comfort threshold $(\mathrm{THI}=$ 72) except on wk 2. Peak hours THI (1130 to $1530 \mathrm{~h}$ ) was observed to be above the thermal comfort zone for all 8 wk of observation.

\section{Behavioral Activities}

The largest differences between treatments in behavioral activities performed during peak hours were observed in wk 2 (Table 2). Cows with access to shade were observed near and facing the water trough 6.4 times less than cows without access, as well as grazing 1.5 times more and lying down 1.8 times more on wk 2 .

No overall differences were observed between total times spent under or outside the shade for the treatment with access to shade (Table 3). However, on wk 2, 
cows spent 3.8 times more total time under the shade (71 vs. $18 \%$ under the shade vs. outside of the shade of the total time observed, respectively), whereas on wk 5 , they spent 4.0 times less total time under the shade (19 vs. $77 \%$ ). Some behaviors were performed more under or outside the shade on individual weeks. Cows with access to shade lay down 13.1 times more under the shade on wk 2 ( 28 vs. $2 \%$ under the shade vs. outside of the shade of the total time observed, respectively) and 4.2 time more under the shade on wk 3 (39 vs. $9 \%$ ), but lay down 4.4 times less under the shade on wk 5 (9 vs. $40 \%$ ). On wk 6 , cows with access to shade performed 3.1 times less "other" behaviors under the shade (3 vs. $9 \%$ under the shade vs. outside of the shade of the total time observed, respectively).

\section{Fly Intensity}

No difference in fly intensity was observed between cows with and without access to shade. Descriptive statistics of fly intensity by treatment across weeks are reported in Table 4.

\section{Daily Lying Time}

Cows with access to shade had a lower daily lying bout frequency on wk $2(9.9 \pm 0.48$ vs. $8.2 \pm 0.48$ bout per day; $P<0.05)$ and a higher daily lying bout frequency on wk $7(7.1 \pm 0.51$ vs. $8.8 \pm 0.51 ; P<0.05)$ than cows without access. Daily lying bout frequency was not different between treatments for the other weeks. Both daily duration of lying and lying mean bout duration were not different between treatments for each week. Descriptive statistics of daily lying time across weeks by treatment are reported in Table 4 .

\section{Vaginal Temperature}

No differences in vaginal temperature were observed between cows with and without access to shade both at $24 \mathrm{~h}$ and peak hours. Descriptive statistics of vaginal temperature across weeks by treatment are reported in Table 4.

\section{Milk Production}

On wk 1 only, cows with access to shade had a lower morning $(11.5 \pm 0.76$ vs. $14.0 \pm 0.75 \mathrm{~kg} ; P<0.05)$ and daily milk production $(21.50 \pm 1.50$ vs. $26.47 \pm$ $1.48 \mathrm{~kg} ; P<0.05)$ than cows without access to shade. Afternoon milk production was not different between treatments on wk 1 . No differences in milk production were observed between treatments after wk 1. Descrip- 


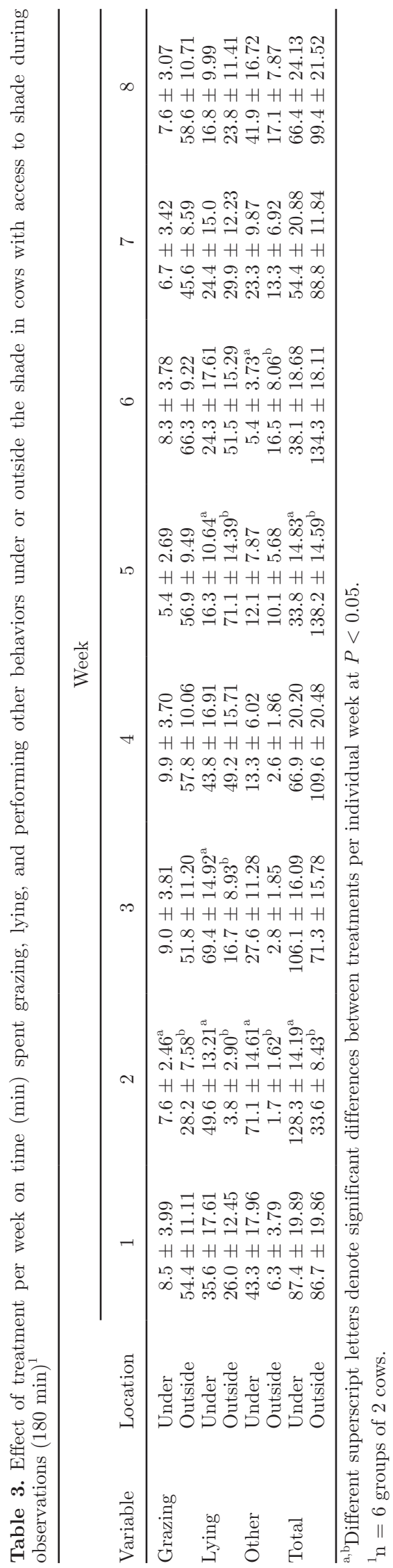

tive statistics of milk production across wk 2 to 8 by treatment are reported in Table 4.

\section{DISCUSSION}

Through the duration of the study, the climatic conditions were within the historical range for the region (daily average and maximum: temperature of 20.7 and $25.8^{\circ} \mathrm{C}$; and THI of 67.2 and 73.6 for the months of July and August; Government of Canada, 2014). Lactating dairy cows are comfortable when THI is below 70,75 to 78 is considered stressful, and above 78 the cow is in extreme distress (Kadzere et al., 2002), making the months of July and August mild in terms of thermal stress, generally with only portions of the days above the threshold. Cows are highly motivated to seek shade as temperatures rise, with a steep increase in motivation when temperature is $>30^{\circ} \mathrm{C}$ (Schütz et al., 2008), making the access to shade during summer a possible sought after resource when available.

Behavioral differences were found between cows with and without access to shade at several observation weeks. However, the largest difference in behavioral activities was observed on wk 2 where average THI was above the comfort threshold level of 72 (Ravagnolo et al., 2000) for the whole $24 \mathrm{~h}$, unlike the other weeks where average THI was above comfort threshold level only during peak hours.

Time spent at the water trough was the most consistent behavior to be affected by access to shade. Cows with access to shade were observed at the water trough up to 6.4 times less than cows without access, and the difference between treatments remained present across weeks. Similarly, previous studies found that lactating cows increased their water intake (Muller et al., 1994) and time around the water trough (Schütz et al., 2010) when little or no shade was available, as heat load increased. A possible method for cattle to reduce heat load is to increase water consumption; indeed, Milam et al. (1986) and Anderson (1985) found that cows that drank cooler water had higher milk production and decreased body temperature. High-milk-producing animals have a rapid water turnover, making them more susceptible to dehydration (Maltz et al., 1984) because milk is $87 \%$ water (Shalit et al., 1991). In addition, evaporating water from the water trough may create a cooler microclimate to which the cows are attracted. Similarly, Legrand et al. (2011) found that cows in a California summer will voluntarily use showers to cool down when kept in open paddocks. Providing dairy cows with shade when temperatures are above their thermal comfort level can potentially help producers reduce water consumption by the cows, which could be significant because the dairy industry has the second 
Table 4. Descriptive statistics by treatment across weeks of vaginal temperature over $24 \mathrm{~h}$ and at peak hours $\left({ }^{\circ} \mathrm{C}\right)$; milk production a.m., p.m., and daily $(\mathrm{kg})$; daily lying bout frequency (bout/d); daily lying mean bout duration ( $\mathrm{min} /$ bout); daily duration of lying $(\mathrm{min} / \mathrm{d})$; and fly intensity (flies/cow) in cows with and without shade access ${ }^{1}$

\begin{tabular}{|c|c|c|c|c|c|}
\hline Variable & Treatment & Mean & $\mathrm{SE}$ & Minimum & Maximum \\
\hline \multirow[t]{2}{*}{ Vaginal temperature 24 -h period ${ }^{2}$} & No shade & 38.6 & 0.2 & 38.4 & 39.3 \\
\hline & Shade & 38.6 & 0.2 & 38.4 & 39.4 \\
\hline \multirow{2}{*}{ Vaginal temperature peak hours ${ }^{2}$} & No shade & 39.1 & 0.2 & 38.7 & 40.3 \\
\hline & Shade & 38.9 & 0.2 & 38.6 & 40.0 \\
\hline \multirow[t]{2}{*}{ Milk production a.m. ${ }^{3}$} & No shade & 13.1 & 0.8 & 12.4 & 14.0 \\
\hline & Shade & 12.6 & 0.8 & 11.5 & 13.3 \\
\hline \multirow[t]{2}{*}{ Milk production p.m. ${ }^{3}$} & No shade & 13.2 & 0.8 & 12.7 & 13.8 \\
\hline & Shade & 12.7 & 0.8 & 11.1 & 13.4 \\
\hline \multirow[t]{2}{*}{ Daily milk production ${ }^{3}$} & No shade & 25.6 & 1.5 & 23.8 & 27.5 \\
\hline & Shade & 24.7 & 1.5 & 21.5 & 26.0 \\
\hline \multirow[t]{2}{*}{ Daily lying bout frequency ${ }^{4}$} & No shade & 7.8 & 0.5 & 6.7 & 8.8 \\
\hline & Shade & 7.9 & 0.5 & 7.1 & 9.9 \\
\hline \multirow{2}{*}{ Daily lying mean bout duration ${ }^{4}$} & No shade & 76.7 & 4.7 & 59.1 & 90.7 \\
\hline & Shade & 76.4 & 4.7 & 54.0 & 87.6 \\
\hline \multirow[t]{2}{*}{ Daily duration of lying ${ }^{4}$} & No shade & 550.5 & 27.9 & 442.9 & 615.1 \\
\hline & Shade & 557.1 & 27.9 & 500.3 & 634.8 \\
\hline \multirow{2}{*}{ Fly intensity ${ }^{4}$} & No shade & 197.7 & 22.4 & 130.6 & 248.6 \\
\hline & Shade & 184.5 & 22.4 & 139.8 & 238.3 \\
\hline
\end{tabular}

${ }^{1}$ Values are least squares means for weeks with no differences between treatments per individual week. Vaginal temperature averages included wk 2 to 7 . Fly intensity averages excluded wk 4 and 7 .

${ }^{2}$ Week $2: \mathrm{n}=11$ groups of 2 cows; wk $3: \mathrm{n}=10$; wk $4: \mathrm{n}=9$; wk $5: \mathrm{n}=8$; wk $6: \mathrm{n}=6$; wk $7: \mathrm{n}=6$.

${ }^{3}$ Week $1: \mathrm{n}=11$ groups of 2 cows; wk 2 to $8, \mathrm{n}=12$.

${ }^{4} \mathrm{n}=12$ groups of 2 cows for all weeks.

highest water footprint in animal production (Mekonnen and Hoekstra, 2012). This could be an important concern in the near future as water will become scarcer (Mekonnen and Hoekstra, 2012).

Cows with access to shade lay down up to 1.75 times more than cows without access, and the difference between treatments remained across weeks. Previous studies (Tucker et al., 2008; Schütz et al., 2010) found that as temperature increases, lying time decreases for both cows with and without access to shade; however, in contrast to our study, they did not find a significant difference in lying time between treatments. During the warmest week (wk 2), cows in both treatments performed other activities, consisting mostly of standing still, close to half of the time they were observed. While cows are standing, an increased amount of surface wind comes into contact with a larger portion of the cow's body, thus allowing for cooling through convection as well as maximizing skin evaporation (Igono et al., 1987). This suggests that standing was most likely a strategy to cool down, used by cows in both treatments during wk 2. Most of the lying and other behaviors performed by the cows with access to shade were performed under the shade, indicating that even if standing can allow for additional cooling through convection and skin evaporation, shade could help further alleviate heat stress. The increase in lying behavior by the cows with access to shade may indicate that they were sufficiently cooled by the shade and did not require additional strategies such as standing and drinking to cool down.

Grazing behavior was up to 1.5 times higher for cows with access to shade compared with cows without access. Conversely, Kendall et al. (2006) found that cows without access to shade had higher grazing times during the day compared with cows with access to portable shades moved at 4- to 5-d intervals; however, cows with access to shade increased grazing time during the night making the overall 24 -h grazing time similar between the 2 groups. In the present study, grazing behavior differences between treatments were observed during the hottest week, despite grazing behavior being the lowest for both treatments during this week. A possible explanation could be that access to shade provides enough thermal relief to compensate for the metabolic heat production associated with herbage consumption. The portable shade also provided the cows with fresh grass under the shade every day allowing the cows to graze without needing to expose themselves to direct heat from the sun at the beginning of the day before feces covered the pasture under the shade. Grazing under the shade was also observed by Tucker et al. (2008) even when grass under the shade structure was mowed to minimize grazing. As temperatures increase, cows stand more and lie down less (Schütz et al., 2010), making the cool nights the best time to lie down during hot summers. Therefore, during warmer days, cows 
may choose to compensate for lower lying times during the day by lying more during the cool nights. This is similar to our results because although cows without access to shade spent less time lying during peak hours on wk 2,3 , and 5 , we observed no difference in overall lying time over $24 \mathrm{~h}$ between treatments. This suggests that cows without access to shade were able to compensate for the lower lying times during peak hours by lying more in other cooler parts of the day.

No differences were found in fly intensity between cows with or without access to shade. Similarly, Kendall et al. (2007) found no differences in insect avoidance behaviors between cows with and without access to shade; these behaviors have been directly associated with fly intensity (Eicher et al., 2001). Odors released by the cow play an important role in its attractiveness to an insect (Torr et al., 2006), and warmer temperatures can cause cows to sweat more and release more odors; however, access to shade may have not modified the physiological state of the cows enough to affect their attractiveness to flies as the cows only spent a portion of the time under the shade and measurements were taken either when the cow was under or outside of the shade.

We did not observe differences in vaginal temperature between cows with and without access to shade for both daily average and peak hours averages. These results are similar to previous studies (Schütz et al., 2010), but contrast with those of Kendall et al. (2007), who found lower body temperatures in cows under the shade during a 90-min period with access to shade when THI was 68.5. The lack of differences between the 2 treatments at peak hours could be due to the fact that cows without access to shade were using other strategies to maintain their body temperature, including drinking more, standing more, and grazing less. In addition, average $24 \mathrm{~h}$ THI was observed to be below the thermal comfort threshold of 72 for all weeks except wk 2. It is possible that the relatively short bout of high THI during the day was not sufficient to cause a significant change in vaginal temperature over the 24 -h period.

No milk production difference was present between treatments except during wk 1 when the cows without access to shade produced more milk in the morning and more daily milk. It is possible that the regrouping of cows into smaller groups for the purpose of the experiment combined with the novelty of the structure caused an initial stress on some cows. Regrouping has been observed to cause some initial decrease in milk production (von Keyserlingk et al., 2008). Starting from wk 2, our results support those reported in other similar studies done in temperate climates by Schütz et al. (2010), in which milk production was not affected by the provision of shade; however, other studies have reported a difference in milk production (Kendall et al., 2006; Fisher et al., 2008).

\section{CONCLUSIONS}

When provided with access to shade, cows spent less time at the water trough, lay down, performed grazing behavior more, and chose to perform behavioral activities, including grazing, under the shade. However, differences in behavioral activities and shade use between cows with and without access to shade were larger when THI was above the cow comfort zone over $24 \mathrm{~h}$. No differences in vaginal temperature or milk production were found between cows with and without access to shade. This suggests that when cows do not have access to shade during Eastern Canadian summers, resorting to other strategies to relieve heat stress is sufficient to prevent negative physiological effects. However, providing access to shade has the potential to greatly decrease water usage in pastured cows and may be an important economic and environmental incentive for adoption by grazers as a suitable strategy to improve cow comfort at pasture.

\section{ACKNOWLEDGMENTS}

We acknowledge the Campbell Centre for the Study of Animal Welfare (Guelph, ON, Canada), the Agricultural Adaptation Council, and Dairy Farmers of Ontario for providing funding. A student scholarship was provided by the Cooperation Council of Ontario through the Young Canada Works Plan. We thank Serge Courchesne and the barn staff at the Organic Dairy Research Centre (ODRC) at the Université de Guelph Campus d'Alfred (Alfred, ON, Canada) for their generous assistance with the animals. We also thank Mélodie Combier (Lycée Enseignement General Technologique Professionel Agricole, Cibeins, France) and Elise Shepley (ODRC) for their assistance with data collection throughout the study.

\section{REFERENCES}

Anderson, M. 1985. Effects of drinking water temperatures on water intake and milk yield of tied-up dairy cows. Livest. Prod. Sci. 12:329-338.

Beede, D. K., and R. J. Collier. 1986. Potential nutritional strategies for intensively managed cattle during thermal stress. J. Anim. Sci. 62:543-554.

Eicher, S. D., J. L. Morrow-Tesch, J. L. Albright, and R. E. Williams. 2001. Tail-docking alters fly numbers, fly-avoidance behaviors, and cleanliness, but not physiological measures. J. Dairy Sci. 84:1822-1828.

Fisher, A. D., N. Roberts, S. J. Bluett, G. A. Verkerk, and L. R. Matthews. 2008. Effects of shade provision on the behaviour, body 
temperature and milk production of grazing dairy cows during a New Zealand summer. N. Z. J. Agric. Res. 51:99-105.

Government of Canada. 2014. Canadian climate normal 1981-2010 station data. Montreal/Mirabel international airport. Accessed Apr. 25, 2014. http://climate.weather.gc.ca/climate_normals/ results_1981_2010_e.html?stnID=5616\&lang=e\&StationName $=$ montreal $\&$ Search Type $=$ Contains $\&$ stnNameSubmit $=$ go\&dCo $\mathrm{de}=1$.

Hernandez-Mendo, O., M. A. G. Von Keyserlingk, D. M. Veira, and D. M. Weary. 2007. Effects of pasture on lameness in dairy cows. J. Dairy Sci. 90:1209-1214.

Higgins, S. F., C. T. Agouridis, and S. J. Wightman. 2011. Shade options for grazing cattle. University of Kentucky, Lexington, College of Agriculture, Cooperative Extension Service.

Igono, M. O., H. D. Johnson, B J. Steevens, G. F. Krause, and M. D. Shanklin. 1987. Physiological, productive, and economic benefits of shade, spray, and fan system versus shade for Holstein cows during summer heat. J. Dairy Sci. 70:1069-1079.

Kadzere, C. T., M. R. Murphy, N. Silanikove, and E. Maltz. 2002. Heat stress in lactating dairy cows: A review. Livest. Prod. Sci. 77:59-91

Kendall, P. E., P. P. Nielsen, J. R. Webster, G. A. Verkerk, R. P. Littlejohn, and L. R. Matthews. 2006. The effects of providing shade to lactating dairy cows in a temperate climate. Livest. Sci. 103:148-157.

Kendall, P. E., G. A. Verkerk, J. R. Webster, and C. B. Tucker. 2007. Sprinklers and shade cool cows and reduce insect-avoidance behavior in pasture-based dairy systems. J. Dairy Sci. 90:3671-3680.

Lachance, S., and G. Grange. 2014. Repellent effectiveness of seven plant essential oils, sunflower oil and natural insecticides against horn flies on pastured dairy cows and heifers. Med. Vet. Entomol. $28: 193-200$.

Legrand, A. L., K. E. Schütz, and C. B. Tucker. 2011. Using water to cool cattle: Behavioral and physiological changes associated with voluntary use of cow showers. J. Dairy Sci. 94:3376-3386.

Legrand, A. L., M. A. G. Von Keyserlingk, and D. M. Weary. 2009. Preference and usage of pasture versus free-stall housing by lactating dairy cattle. J. Dairy Sci. 92:3651-3658.

Maltz, E., K. Olsson, S. M. Click, F. Fyhrquist, N. Silanikove, I. Choshnia, and A. Shkolnik. 1984. Homeostatic responses to water deprivation or hemorrhage in lactating and non-lactating Bedouin goats. Comp. Biochem. Physiol. A 77:79-84.

Mekonnen, M. M., and A. Y. Hoekstra. 2012. A global assessment of the water footprint of farm animal products. Ecosystems (N. Y.) 15:401-415.

Milam, K. Z., C. E. Coppock, J. W. West, J. K. Lanham, D. H. Nave, J. M. Labore, and C. F. Brasington. 1986. Effects of drinking water temperature on production responses in lactating Holstein cows in summer. J. Dairy Sci. 69:1013-1019.
Muller, C. J. C., J. A. Botha, and W. A. Smith. 1994. Effect of shade on various parameters of Friesian cows in a Mediterranean climate in South Africa. 1. Feed and water intake, milk production and milk composition. S. Afr. J. Anim. Sci. 24:49-55.

Ominski, K. H., A. D. Kennedy, K. M. Wittenberg, and S. A. Moshtaghi Nia. 2002. Physiological and production responses to feeding schedule in lactating dairy cows exposed to short-term, moderate heat stress. J. Dairy Sci. 85:730-737.

Ravagnolo, O., I. Misztal, and G. Hoogenboom. 2000. Genetic component of heat stress in dairy cattle, development of heat index function. J. Dairy Sci. 83:2120-2125.

Schütz, K. E., N. R. Cox, and L. R. Matthews. 2008. How important is shade to dairy cattle? Choice between shade or lying following different levels of lying deprivation. Appl. Anim. Behav. Sci. 114:307-318.

Schütz, K. E., A. R. Rogers, N. R. Cox, J. R. Webster, and C. B. Tucker. 2011. Dairy cattle prefer shade over sprinklers: effects on behavior and physiology. J. Dairy Sci. 94:273-283.

Schütz, K. E., A. R. Rogers, Y. A. Poulouin, N. R. Cox, and C. B. Tucker. 2010. The amount of shade influences the behavior and physiology of dairy cattle. J. Dairy Sci. 93:125-133.

Shalit, U., E. Maltz, N. Silanikove, and A. Berman. 1991. Water, sodium, potassium, and chlorine metabolism of dairy cows at the onset of lactation in hot weather. J. Dairy Sci. 74:1874-1883.

Torr, S. J., T. N. C. Mangwiro, and D. R. Hall. 2006. The effects of host physiology on the attraction of tsetse (Diptera: Glossinidae) and Stomoxys (Diptera: Muscidae) to cattle. Bull. Entomol. Res. 96:71-84

Tucker, C. B., A. R. Rogers, and K. E. Schütz. 2008. Effect of solar radiation on dairy cattle behaviour, use of shade and body temperature in a pasture-based system. Appl. Anim. Behav. Sci. 109:141-154.

Valtorta, S. E., P. E. Leva, and M. R. Gallardo. 1997. Evaluation of different shades to improve dairy cattle well-being in Argentina. Int. J. Biometeorol. 41:65-67.

Vasseur, E., J. Rushen, D. B. Haley, and A. M. de Passillé. 2012. Sampling cows to assess lying time for on-farm animal welfare assessment. J. Dairy Sci. 95:4968-4977.

von Keyserlingk, M. A. G., D. Olenick, and D. M. Weary. 2008. Acute behavioral effects of regrouping dairy cows. J. Dairy Sci. 91:10111016.

Washburn, S. P., S. L. White, J. T. Green Jr., and G. A. Benson. 2002. Reproduction, mastitis, and body condition of seasonally calved Holstein and Jersey cows in confinement or pasture systems. J. Dairy Sci. 85:105-111.

Woolley, C. 2013. Attack intensity of pest flies and the behavioural responses of pastured dairy cows. MSc Thesis, University of Guelph, Guelph, Ontario, Canada. 